\title{
Attitudes of Indian Dental Professionals towards Information Technology - A Cross Sectional Study
}

\author{
Parthkumar Kamleshbhai Thakkar¹, Neeta Vijay Bhavsar², Ekta Milanbhai Shah ${ }^{3}$, Siddhant Kulmendra Taneja4, \\ Hetul Ketankumar Patel ${ }^{5}$, Vyoma Sanjaybhai Sheth ${ }^{6}$, Noopur Sapnesh Shah ${ }^{7}$, Anuj Vasantray Mansata8
}

\begin{abstract}
${ }^{1}$ Department of Public Health Dentistry, Karnavati School of Dentistry, Karnavati University, Uvarsad, Gandhinagar, Gujarat, India. ${ }^{2}$ Department of Periodontology, Government Dental College and Hospital, Civil Campus, Asarwa, Ahmedabad, Gujarat, India. ${ }^{3}$ Department of General Dentistry, Community Health Centre, Sariyad, Patan, Gujarat, India. ${ }^{4}$ Department of Public Health, University of South Florida, College of Public Health, USA. ${ }^{5}$ Department of Public Health Dentistry, Karnavati School of Dentistry, Karnavati University, Uvarsad Gandhinagar, Gujarat, India. ${ }^{6}$ Department of Bioinformatics and Computational Biology, University of South Florida, Morsani College of Medicine, USA. ${ }^{7}$ Department of Public Health Dentistry Narsinhbhai Patel Dental College and Hospital, Visnagar, Gujarat, India. ${ }^{8}$ Department of General Dentistry, Community Health Centre, Kolavada, Mehsana, Gujarat, India.
\end{abstract}

\section{ABSTRACT}

\section{BACKGROUND}

There have been substantial advances in the field of information technology (IT) which has led to the development of computer networks which allow access to an enormous amount of data. In 1971, computer was first introduced in dentistry and since then it has positively impacted the dental students' attitudes and perceptions towards information technology.

\section{METHODS}

A pretested, structured, multisection electronic survey (e-survey) form was used which was prepared using Google Forms. The questionnaire was distributed among a group of people by forwarding and posting of Google survey form link through WhatsApp groups, sending an invitation via e-mail, and distribution of printed questionnaires to health professionals to participate in the study. Data was automatically collected in Google Drive. Necessary statistical analysis was performed using the statistical software package SPSS (Chicago, IL, USA) version 22.0 for MS Windows \& $\mathrm{P}<0.05$.

\section{RESULTS}

The response rate was higher among females than males i.e. $57 \%$ and $43 \%$ for females and males respectively. Among participants, students were highest in number (35\%) followed by academicians (30\%), self-employed (26\%) and lowest was associate health professionals (9\%). When asked about making computer training a part of the undergraduate curriculum, a majority (84\%) of respondents suggested 'Yes', few (12\%) suggested 'No' and only 'very few' (4\%) were uncertain.

\section{CONCLUSIONS}

Results of this study highlighted the fact that there was easy access to a computer and internet among dental health professionals in India. Many potential applications of information technology in dentistry depend on the familiarity of the health professional to computers and advancing technology.

\section{KEY WORDS}

Dental Health Professionals, Information and Communication Technology, Information Technology
Corresponding Author: Dr. Parthkumar Kamleshbhai. Thakkar, Reader, Department of Public Health Dentistry, Karnavati School of Dentistry, Karnavati University, Uvarsad, Gandhinagar, Gujarat, India. E-mail: parthth11@gmail.com

DOI: $10.14260 /$ jemds/2020/445

How to Cite This Article: Thakkar PK, Bhavsar NV, Shah EM, et al. Attitudes of Indian dental professionals toward information technology- a cross sectional study. J. Evolution Med. Dent. Sci. 2020;9(29):2045-2048, DOI: $10.14260 /$ jemds/2020/445

Submission 14-03-2020,

Peer Review 10-06-2020,

Acceptance 16-06-2020,

Published 20-07-2020.

Copyright (C) 2020 JEMDS. This is an open access article distributed under Creative Commons Attribution License [Attribution 4.0 International (CC BY 4.0)] 


\section{BACKGROUND}

Information technology and computing is one of the fastest growing fields. The computer is one of the greatest inventions of the $20^{\text {th }}$ century and it has changed the world in many ways. Computer has made tremendous contribution to nearly all the fields including dentistry. ${ }^{1}$ There have been substantial advances in the field of information technology (IT) which has led to the development of computer networks which allows access to an enormous amount of data. ${ }^{2}$ In 1960, the internet was introduced by the United States of America's military to establish workable communication in the event of a strike by enemy missiles or forces. ${ }^{3}$ In 1971, Computer was first introduced in dentistry and since then it has positively impacted the dental students' attitudes and perceptions toward information technology. ${ }^{1}$

The combined use of computers and the internet has helped with the rapid development of IT and it has changed the environment in which study and practice dentistry. Many disciplines have been benefitted with the usage of IT including dentistry. Nowadays, it is imperative to be computer literate as information technology has paved its way into all walks of life. There are many potential applications of information technology in dentistry through the amalgamation of principles of technological advances and dentistry such as patient care, dental education, patient education, communication and information about new products, continuing dental education, access to recent dental literature, marketing, settling insurance claims, quality assurance, dental research, administration, electronic dental records, teledentistry, design and production, digital radiography, digital photography and many more. There are more than 300 dental colleges in India with nearly 30,000 undergraduates passing every year but training of these young budding dentists regarding use of computer and information technology is minimal compared to their counterparts in western countries which are so well trained. It is imperative for dental students to be a computer literate nowadays. Today many dental schools require students to purchase computers and others are developing strategies to integrate dental informatics in routine practice.

A small change of inclusion of computer education in dental curriculum can have big impact on dental practice in future. In this era of globalization, dental practice in different parts of world has become more and more competitive. In developed countries, the use of the internet is more prominent as compared to developing countries where computer literacy and internet use are low and slowly improving. Limited financial resources are the greatest challenges for developing country like India. ${ }^{4}$ Recently, in India overall data consumption has increased so it is speculated this increase would be reflected among health professionals use for educational and clinical purposes. ${ }^{4}$ Certainly, introduction of computers has increased overall performance for dental education and has instilled positive attitudes towards computers and teaching. While many studies have reported literacy and internet use among dental professionals but only few studies have reported perception and attitudes of Indian dental professionals toward information technology. There for aim of present study is to assess the level of computer and information technology use among Indian dental health professionals.

\section{METHODS}

A cross sectional study was conducted using a pretested, structured, multisection electronic survey (e-survey) form. The questionnaire was prepared using Google Forms. An extensive review of previous research was undertaken to find suitable questions. The content of the e-survey form was decided in consultation with experts in the fields of survey research. This multisection questionnaire included questions about A) socio-demographic data B) Access to and general skill for the use of information technology C) Computers in education. The present study was carried out at Karnavati School of Dentistry, Karnavati University, Uvarsad, Gandhinagar. Necessary ethical clearance was obtained from the Karnavati School of Dentistry Ethics Committee (KSDEC). The questionnaire was distributed among a group of people by forwarding and posting of Google survey form link through WhatsApp groups, sending an invitation via e-mail, and distribution of printed questionnaires to health professionals to participate in the study. Non-respondents were contacted again 2 weeks later to ensure a high response rate. There was a response rate of $79 \%$ (277 out of 350). A confidential Google Spreadsheet was maintained in the principal investigator's Google Drive where all respondents' responses were automatically collected.

\section{Statistical Analysis}

The statistical analysis was performed using the statistical software package SPSS (Chicago, IL, USA) version 22.0 for MS Windows \& $\mathrm{p} \leq 0.05$ was considered statistically significant.

\section{RESULTS}

The response rate was higher among females than males i.e. $57 \%$ and $43 \%$ for females and males respectively (Figure 1). Among participants, Students were highest in number (35\%) followed by Academicians (30\%), Self-employed (26\%) and lowest was Associate health professionals (9\%), (Figure 2). When participants were asked that do they access to the computer, $94 \%$ of participants said yes and only negligible (6\%) of participants said No (Figure 3). When asked about computer activities majority (242) of participants suggested that Internet surfing was their favourite activity among others followed by PowerPoint presentation (194), Entertainment (184), Word processing (144), Multimedia (137), Data management (105), least number (94) opted for Online database search (Table 1). When asked about role of computers in education, highest number of participants (191) suggested that Computers make life easy followed by Internet can be very useful for searching information (172), Computer is boon to academics (141), Advanced computer training should be made accessible to those who are interested in college (126), College should adopt electronic format for academics and patient management, and only a few (24) indicated that computer is for fun (Table 2). Regarding grading of access and availability of computers (Figure 4), 40\% of subjects indicated that they had very good access and availability to computers followed by Good (39\%), Adequate (16\%), Poor (5\%). When respondents were asked to grade 
their general IT skills, a majority (74\%) suggested that they had Average skills followed by Expert (15\%), Beginner (9\%) and only $2 \%$ of respondents were unfamiliar with general IT skills (Figure 5). When asked about making computer training a part of the undergraduate curriculum, a majority (84\%) of respondents suggested Yes, few (12\%) suggested No and only very few $(4 \%)$ were uncertain (Figure 6).
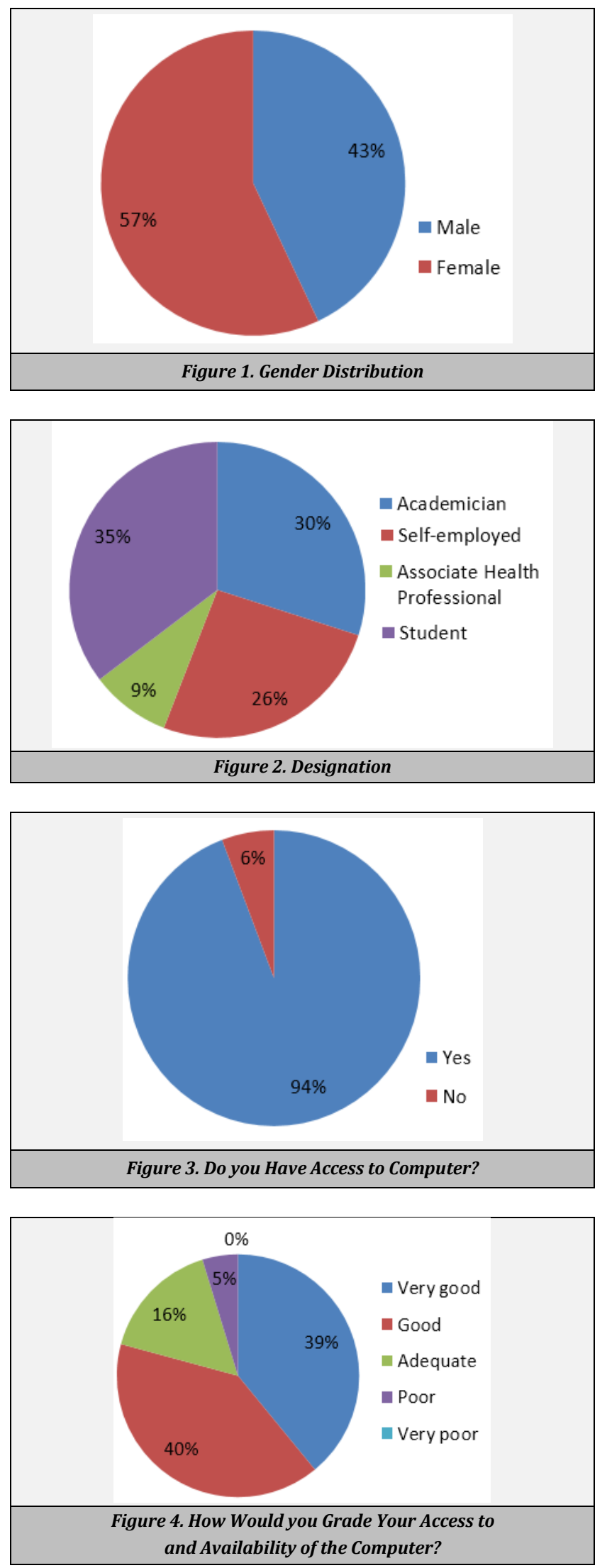
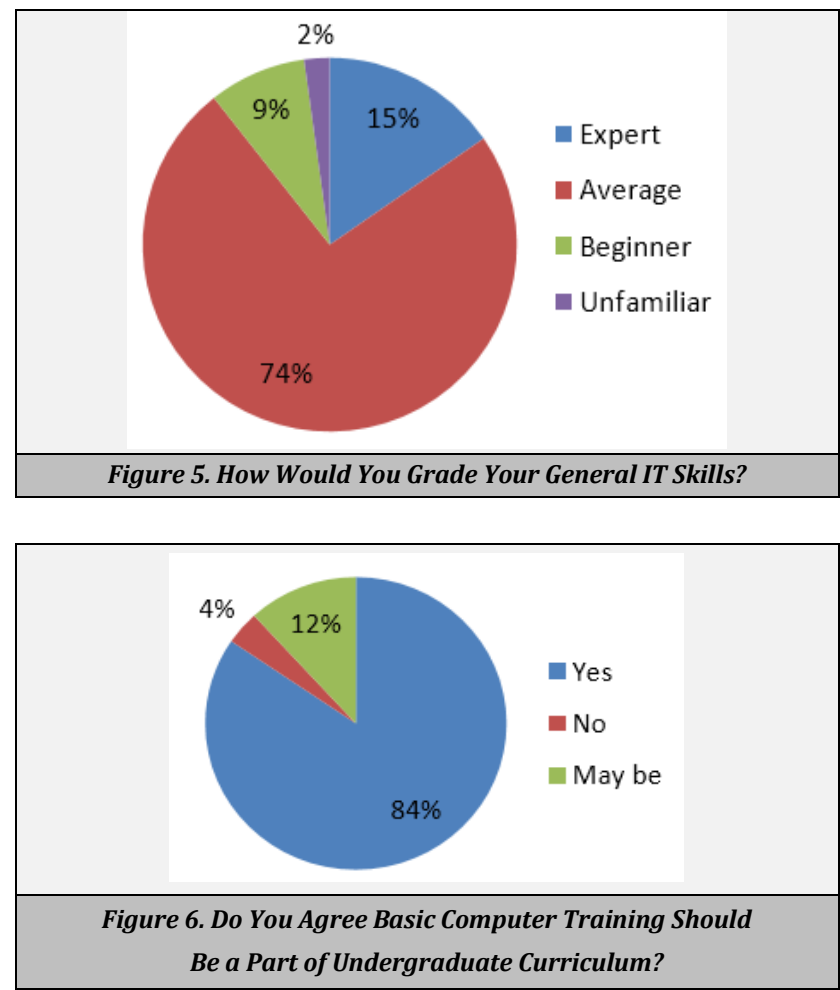

\begin{tabular}{|cc|}
\hline & Number of Respondents \\
Digital photography & 164 \\
Digital radiography & 180 \\
Electronic referral forms & 56 \\
Paperless forms & 85 \\
None of the above & 43 \\
Others & 2 \\
\hline Table 1. Use of Information Technology \\
\hline
\end{tabular}

\begin{tabular}{|cc|}
\hline Computers make life easy & $\begin{array}{c}\text { Number of } \\
\text { Respondents }\end{array}$ \\
Computer is a boon to academics & 191 \\
Computer is for fun & 141 \\
Internet can be very useful for searching information & 24 \\
Advanced computer training should be made accessible to & 172 \\
those who are interested by the college & 126 \\
Typing on computer is easy than writing on paper & 42 \\
College should adopt electronic format for academics and & 109 \\
patient management & 1 \\
\hline Others & \\
\hline Table 2. Computers in Education & \\
\hline
\end{tabular}

\section{DISCUSSION}

The present study was conducted among various Indian health professionals such as students, academicians, self-employed dentists, and associate health professionals to explore their perceptions and attitudes toward information technology. In this age of the internet, one should know how to use a computer for better advancement in their discipline. Knowledge of computers and skills to use it effectively and efficiently has become essential in dental practice and education..$^{5}$ Overall, the use of computers has a positive impact on dentistry. ${ }^{6}$ and the internet has become the most preferred method for surfing any kind of information. ${ }^{7}$ Still, there is a digital divide among those who use computers and the internet as some are comfortable using computers but many are not. ${ }^{1}$ In India, only a few studies have been reported which include a variety of dental health professionals. The response rate was slightly higher amongst females (57\%) compared to 
males $(47 \%)$. The reason for this finding might be the higher general admission rate $(70 \%)$ among females in dentistry. ${ }^{8}$ previous studies have also reported higher response rate of females compared to males. ${ }^{9}$ Previous study reported that computer access among dental students were $98.4 \%$ and 94.4\% in Tamilnadu and Andhra Pradesh respectively which was similar to present study $94 \%$. J Hamissi reported $94.7 \%$ of the participant had computer access at home which was similar to the present study. ${ }^{9} \mathrm{G}$ Rhman reported $100 \%$ had computer access and most of them used the computer at home. ${ }^{10}$ Such easy access to computers can be used as a useful tool to improve educational use in terms of presentation, data management, and research. In the present study, it was found that the majority of participants used computers for the Internet surfing followed by PowerPoint Presentation, Entertainment, Word processing, Multimedia, Data management, least number opted for Online database search. Dental students mostly use the computer for the Internet which is in accordance with the present study. ${ }^{11}$ A study conducted by Mohamed at el. suggested that information and communication technology helped to do an efficient presentation. ${ }^{12}$ The previous study has reported that entertainment was one of the most popular uses of computers which were similar to the present study. ${ }^{4}$ The display of lectures as PowerPoint presentations were the most common use of computer and it was found to be the general attitude. ${ }^{11}$ A study conducted by Gaikwad DV at el. found that approximately $60 \%$ of respondents used IT for internet surfing, data entry, creating graphs, and statistical analysis. ${ }^{13}$ In present most of participants suggested that computers make life easy, it's a boon to academic and college should provide advanced training to those who are interested for learning. Almost half proportion of dental students of Tamilnadu and Andhra Pradesh indicated that they had good access and availability of computers ${ }^{11}$ whereas the present study found that $40 \%$ had very good access and availability to computers followed by Good access and availability (39\%). The reason for this difference could be better awareness and the availability of computers these days. A study conducted by TB Chowdhary at el. showed that more than half of dental students of Tamilnadu and Andhra Pradesh were competent in some basic skills regarding general IT usage ${ }^{11}$ which was in accordance with the present study but only 15\% participants were Expert. G Rahman reported that almost half (51.33\%) has good computer skills and $35.84 \%$ had excellent computer skills. ${ }^{10}$ In contrast, the present study reported that $74 \%$ had average IT skills and only 15\% were experts, this difference might be due to exposure to computers at an early age and extensive use of computers. Probably this was the only study which found that $84 \%$ of participants suggested computer should be training a part of the undergraduate curriculum.

\section{CONCLUSIONS}

The results of this study highlighted the fact that there was easy access to a computer and internet among dental health professionals in India. Many potential applications of information technology in dentistry depend on the familiarity of the health professional to computers and advancing technology. Further research is suggested to evaluate the general perceptions and attitudes of dental health professionals towards information technology which affects the successful implementation of information technologyenabled solution in dentistry.

\section{REFERENCES}

[1] Gupta P, Gupta SG, Ankola AV, et al. Computer use among post graduate dental students in India. Journal of Oral Health \& Community Dentistry 2014;8(3):135-42.

[2] Arora R. Computer and information technology skills of first year medical and dental students at CMC Ludhiana. Health Administrator 2005;17(1):54-8.

[3] December J, Randall N. The world wide web unleashed. $1^{\text {st }}$ edn. Sams 1994.

[4] Kumar S, Tadakamadla J, Tibdewal H, et al. Internet usage among undergraduate dental students in India. Revista Odonto Ciencia 2010;25(3):261-5.

[5] Vijayalakshmi P, Math SB. Response and attitudes of undergraduate nursing students towards computers in health care. Canadian Journal of Nursing Informatics 2013;8(3 \& 4).

[6] Harikumar K, Gopinath S, Raghunath A, et al. Computers and internet in dental education system of Kerala, South India: a multicentre study. J Int Clin Dent Res Organ 2015;7(1):82-4.

[7] Jali PK, Singh S, Babaji P, et al. Knowledge and attitude about computer and internet usage among dental students in Western Rajasthan, India. J Int Soc Prev Community Dent 2014;4(1):29-34.

[8] Kancharla B. Unlike in engineering \& pharmacy, females make up for $70 \%$ of the students enrolled for BDS.

[9] Hamissi J, Gholami S, Hamissi H. The emerging role of computer literacy in improving the performance of dental students. International Journal of Collaborative Research on Internal Medicine \& Public Health 2013;5(8).

[10] Rahman G. Use of computers among students of dental college in Saudi Arabia. J Educ Ethics Dent 2011;1(1):127.

[11] Chowdary TB, Kathirvel A, Ganesh R. Knowledge regarding usage of computer among Indian dental students. Journal of Evolution of Medical and Dental Sciences. 2013;2(49):9502-10.

[12] Mohamed AM, Aik TC, Yi LP, et al. Dental students' attitudes and perceptions towards ICT resources and skills. Procedia Social and Behavioral Sciences 2011;18:400-3.

[13] Gaikwad DV, Pereira DR, Mudholkar PP, et al. Study of Role of Information technology in research by dentists in the dental colleges in Mumbai. International Journal of Scientific and Engineering Research 2017;8(5):1-4. 